\title{
Rosario Camacho. Su docencia e investigación en el ámbito del Patrimonio Histórico
}

\author{
María Morente \\ Universidad de Málaga
}

Hay personas que trazan caminos y despejan nuevos senderos, que acompasan sus certezas con su compromiso, con la defensa apasionada y lúcida de aquello en lo que creen. Hay personas que nos acompañan en nuestras primeras búsquedas, confiando en nosotros pese a nuestra inexperiencia y que establecen lazos que permanecerán para siempre. Hay personas que por todo esto dejan una huella indeleble y les reconocemos y llamamos maestros.

Todo esto evoca lo que siento cuando relaciono a Rosario Camacho con el Patrimonio. $Y$ necesito expresarlo así, porque su contribución científica -brillante también en este campo- se completa con su compromiso valiente y perseverante en los debates y conflictos locales, con su prolífera docencia y con la introducción de esta disciplina.

Rosario Camacho fue pionera en la implantación del Patrimonio Histórico en la Universidad Española, capitaneando desde la década de los ochenta una de las líneas de investigación del

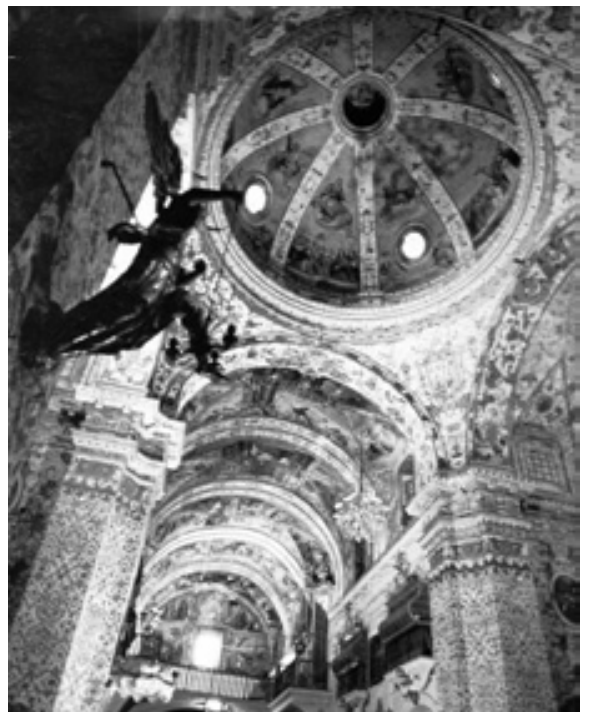

Departamento de Historia del Arte de Málaga, hoy plenamente consolidada. Apostó por la materia con intuición y valentía en una época en que la disciplina patrimonial comenzaba a esbozarse, propiciando reflexiones sobre el papel del historiador del arte ${ }^{1}$, un tema vertebral para ella, y consolidando una asignatura en la licenciatura y actualmente grado, que bajo la denominación de

1 CAMACHO MARTÍNEZ, R., "El historiador del Arte ante el reto del Patrimonio», Congreso Nacional Clío y el Geómetra. El vigía de Tierra, n. ${ }^{\circ}$ 6, Melilla, 1998. 
Introducción al Patrimonio, ha formado desde entonces a nuestros alumnos.

La actividad de la doctora $\mathrm{Ca}$ macho siempre ha sido plural, diversa, prolífera, tanto por la variedad de temas que abarca como por la propia naturaleza de sus trabajos, materializados a través de publicaciones, proyectos de investigación, dirección de memorias de licenciatura y tesis doctorales, la implicación directa en comisiones y órganos asesores, la elaboración de documentos de catalogación o inventario para las Administraciones públicas o su frecuente activismo en las polémicas ciudadanas en defensa de los bienes patrimoniales.

Toda esta actividad polifacética es difícil sintetizarla en el reducido espacio de esta reseña, por lo que me gustaría mencionar, al menos, las dos temáticas que considero vertebran su trayectoria en el Patrimonio Histórico.

Un tema recurrente para ella es la ciudad histórica. Sus monumentos, los sistemas de registro -inventarios y catálogos- el planeamiento urbanístico y las guías. Su libro sobre la Málaga Barroca $^{2}$ o sus trabajos sobre la Catedral $\mathrm{u}$ otros monumentos han sido siempre un referente para la redacción de los proyectos de rehabilitación de los ar- quitectos locales. $\mathrm{Y}$ las seis carpetas publicadas por el Colegio de Arquitectos entre 1986 y 1987 fueron pioneras en la lectura patrimonial de la arquitectura malagueña ${ }^{3}$.

Su labor sobre la Guía de Málaga se inició con la dirección y redacción del Inventario Histórico Artístico de Málaga y su Provincia por encargo del Ministerio de Cultura en 1981 (publicado en 1985), y continuó con un proyecto de investigación de la Dirección General de Universidades de la Junta de Andalucía en 1987. Se sumó su dirección de los trabajos para la redacción del Catálogo de edificios protegidos del Plan Especial del Centro Histórico de Málaga en 1988, o del Patrimonio Municipal diez años después. Todas estas iniciativas dieron como fruto, también, una publicación clave: la Guía Histórico Artístico de Málaga, publicada por la editorial Arguval en 1992, y revisada y reeditada, dado su éxito de ventas, en 1997 y 2006. Un libro de cabecera para profesionales o amantes de la ciudad, que ha sido la única guía razonada sobre Málaga y su arquitectura hasta época muy reciente.

El patrimonio urbano y arquitectónico de Melilla, su ciudad natal, ha sido también uno de sus objetos de investi-

2 Publicación de su tesis doctoral por la Universidad de Málaga en 1981.

3 Realizadas en colaboración con el arquitecto José María Romero, estas publicaciones sobre la Iglesia de San Felipe Neri, el Palacio de los Condes de Villalcázar, la Ermita de Zamarrilla, el Santuario de la Victoria, La Casa del Real Montepío o la Iglesia del Sagrario, presentan un levantamiento planimetrico y una lectura artística, arquitectónica y patrimonial de estos inmuebles. 
gación. Por encargo de la ciudad realizó en 2005 un trabajo de especial envergadura: el expediente para su propuesta de declaración de Patrimonio Mundial. Y en un ámbito territorial más extenso, se debe citar su dirección del equipo de la Universidad de Málaga en el proyecto de la Comunidad Europea Patrimonio partagés entre 2002-20054, o la codirección de distintos cursos de especialización sobre la ciudad histórica.

Otro tema central de su trayectoria en el ámbito patrimonial ha sido la pintura mural, las arquitecturas pintadas de las ciudades de Málaga y MeliIla. Una línea de trabajo iniciada con un proyecto del Ministerio de Cultura en 1996 conjuntamente para ambas ciudades, y desarrollada mediante nuevos proyectos I+D a partir de 2003. Una línea consolidada mediante la dirección de una tesis doctoral y numerosas publicaciones posteriores, que ha tenido como frutos descubrir, documentar, inventariar y reconocer este extenso patrimonio desatendido por las administraciones públicas hasta hace relativamente poco tiempo y que gracias a estos trabajos hoy gozan de protección jurídica y reconocimiento social.

La singularidad de la doctora Camacho ha sido no reducir sus contribuciones al aspecto teórico, sino participar de forma activa con las ad- ministraciones públicas en Comisiones Asesoras, lo que ha posibilitado que su conocimiento y sus opiniones hayan gozado de trascendencia en la toma de decisiones. Su presencia como vocal en la Comisión Provincial de Patrimonio Histórico de la Consejeria de Cultura desde 1981 a la actualidad le ha permitido opinar y defender innumerables proyectos de toda la provincia. Resaltaría entre otros, su enardecida defensa de la barriada del Bulto, la Casa de la Cultura, el Silo del Puerto, el Convento de Santo Domingo, o la Casa de las Monjas, entre otras muchas intervenciones en los Conjuntos Históricos de Archidona, Ronda, Antequera, Frigiliana, Mijas, Macharaviaya o Vélez Málaga.

Su participación en el Plan Estratégico de Málaga, en la Comisión de la candidatura Málaga 2016, en la Comisión de Bienes Inmuebles y bienes Muebles de la Junta de Andalucía ratifican este compromiso constante. Realmente no ha habido en la ciudad ninguna polémica local sobre la conservación del Patrimonio en la que Rosario Camacho no haya hecho oír su voz, desde la Academia de Bellas Artes de San Telmo, desde el Departamento de Historia del Arte o desde algunas de estas comisiones asesoras.

No quisiera terminar esta breve reseña sin apuntar otro aspecto que

4 Patrimoines Partagés: savoirs et savoir-faire apliqués au patrimoine architectural et urbain des XIX$\mathrm{XX}$ siécles en Mediterranée. Comunidad Europea. 
creo que define y caracteriza a la Doctora Camacho. Su curriculum vitae es desbordante, pero no es fruto de un trabajo en solitario. Casi todas sus iniciativas docentes e investigadoras han generado becarios y colaboradores. Es incontable el número de alumnos, ex alumnos o jóvenes profesionales que hemos podido participar en sus trabajos. Realmente digno de mención de su perfil es el número de memorias de licenciaturas y tesis doctorales que de variados temas de historia del arte ha dirigido. Entre ellas, desde 1996 a la actualidad podemos contabilizar unas ocho tesis doctorales cuyo tema central es el Patrimonio Histórico o Cultural enfocada desde el ámbito metodológico de esta disciplina.
El compromiso de Rosario Camacho por el Patrimonio, como decía, ha abierto puertas a muchos alumnos y profesionales y ha implantado en la Universidad de Málaga una disciplina hoy consolidada a través del perfil de profesores, proyectos, los planes docentes del Departamento de Historia del Arte y que se refleja igualmente en su actual máster de postgrado Desarrollos Sociales de la Cultura Artística, cuya implantación coordinó junto al doctor Carmona Mato.

En nombre de todos los que nos hemos formado bajo esta tenaz, lúcida, constante, y generosa entrega, y en nombre de todos los que aún han de llegar a nuestras aulas y disfrutarán de tu legado, muchas gracias Charo. 